\title{
Immunocytochemistry of mucosal changes in patients infected with the intestinal nematode Strongyloides stercoralis
}

Centro de Pesquisas

\section{Aggeu}

Magalhaes/FIOCRUZ,

Caixa Postal No 7471, CEP: 50670-420,

Recife, Brazil

H B Coutinho

T I Robalinho

V B Coutinho

Department of

Gastroenterology,

Federal University of

Pernambuco, Brazil

$\mathrm{J}$ R Almeida

J T O Filho

Department of

Pathology, University

of Aberdeen

G King

Department of

Pathology, University

of Nottingham

D Jenkins

Department of Medicine, University of Nottingham

Y Mahida

Department of Immunology,

University of

Nottingham

H F Sewell

Department of Life Science, University of Nottingham

D Wakelin

Correspondence to: Professor D Wakelin Department of Life Science, University of Nottingham, Nottingham NG7 2RD.

H B Coutinho, T I Robalinho, V B Coutinho, J R Almeida, J T O Filho, G King, D Jenkins, Y Mahida, H F Sewell, D Wakelin

\begin{abstract}
Aim-To investigate the immunopathological changes in duodenal tissues induced by strongyloidiasis and to relate these to degrees of clinical severity.

Methods-Tissues taken from 21 patients showing mild, moderate or severe symptoms of strongyloidiasis, and from noninfected controls, were sectioned and stained immunocytochemically for IgA, secretory component (SC) and HLA-DR. Immunopathology was assessed by changes in numbers, intensity and distribution of stained cells.

Results-Parasitised individuals showed villous atrophy and crypt hyperplasia. There was notable infiltration of the lamina propria by IgA positive plasma cells and of the epithelium by intraepithelial lymphocytes. Infection was also associated with increased expression of SC and decreased expression of HLA-DR in epithelial cells. Changes in all parameters correlated with degree of clinical severity. Conclusions-Profound mucosal changes are induced by strongyloidiasis. Some are analogous to those seen in coeliac disease, but others seem quite unusual. It is likely that these changes are functionally related to the immunopathophysiological consequences of infection seen in patients with severe disease.
\end{abstract}

(F Clin Pathol 1996;49:717-720)

Keywords: strongyloidiasis, unusual mucosal changes, immunopathology.

The parasitic nematode Strongyloides stercoralis infects millions of people in tropical and subtropical regions as well as travellers from developed countries. Infections are acquired when larvae penetrate the skin and migrate to mature in the small bowel. The interest of strongyloidiasis to clinicians lies in the nature of the associated pathology, the potential for long term debilitating illness ${ }^{1}$ and exacerbation of infection by immune suppression. ${ }^{2}$ The adult worms (parthenogenetic females) live among the villi, laying eggs which hatch to release larvae that pass out with stools. Infection can be maintained within the patient, sometimes for decades, by autoinfection, whereby larvae reinvade without leaving the body. In immunocompromised individuals this process can produce a massive, life threatening hyperinfection involving many organs. ${ }^{2}$ In immunocompetent patients pathology is re- stricted to the small bowel and varies in severity according to the numbers of worms present. Almeida ${ }^{3}$ categorised the symptoms associated with strongyloidiasis into mild, moderate and severe, on the basis of levels of infection and clinical assessment of the degrees of malaise, abdominal pain, vomiting, and diarrhoea. Patients with severe symptoms can show uncontrolled vomiting and a bloody mucus diarrhoea, and may suffer from dehdration and malnutrition. These three categories are similar to those described on the basis of histopathology. ${ }^{4}$

To our knowledge no reported studies have been made of the duodenal pathology associated with strongyloidiasis in immunocompetent patients using immunocytochemical techniques that permit identification and analysis of immune or inflammatory cells. The purpose of this initial study was to look for correlations between intestinal immunopathology and clinical symptoms of strongyloidiasis. A variety of monoclonal and polyclonal antibodies was used to examine immunological aspects of the histopathological changes seen in Brazilian patients presenting with the categories of symptoms defined above. Our data have revealed some pathological changes that are novel for an intestinal infection and others that are strikingly similar to inflammatory bowel conditions, particularly coeliac disease.

\section{Methods}

TISSUES

Duodenal biopsy material was available from a large number of patients with strongyloidiasis registered at the Gastroenterology Outpatient Clinic of the Federal University of Pernambuco Hospital. For the purposes of this study 21 patients were selected, of whom seven (three women and four men; age range 19-67 years) had mild symptoms, seven (four women and three men; age range 21-36 years) had moderate symptoms and seven (one woman and six men; age range 29-51 years) had severe symptoms, the latter having been treated at the University Hospital intensive care unit; none of the patients had the hyperinfection syndrome. Selection was based on strict criteria. Patients who had recently received immune suppressive treatment were excluded from the study, as were patients with other intestinal infections. Particular care was taken to screen for giardiasis; none of the 21 individuals studied had this infection. Control tissues were taken from two uninfected patients presenting with unrelated 
conditions in Recife and at the Queen's Medical Centre, University of Nottingham.

IMMUNOHISTOLOGY

Biopsy specimens from the upper small intestine were taken during endoscopy, fixed in $10 \%$ formalin, dehydrated in ethanol, cleared in xylene, and embedded in paraffin wax. Sections cut at $5 \mu \mathrm{m}$ were mounted on slides previously treated with a $2 \% 3$-aminopropyltrimethoxysilane solution in acetone for 10 minutes. After mounting, the sections were dried at $37^{\circ} \mathrm{C}$ for 48 hours.
Dewaxing of sections, endogenous peroxidase blockade and immunostaining by the Streptavidin biotin complex technique for monoclonal and polyclonal antibodies was performed as described previously. ${ }^{5}$ Negative controls for the monoclonal system comprised parallel sections treated with Tris buffered saline in place of primary antibody. For the polyclonal system, negative controls were provided in similar sections by substitution of primary antibody with a dilution of normal rabbit immunoglobulin fraction. The primary antibodies used were: anti-IgA rabbit polyclo-
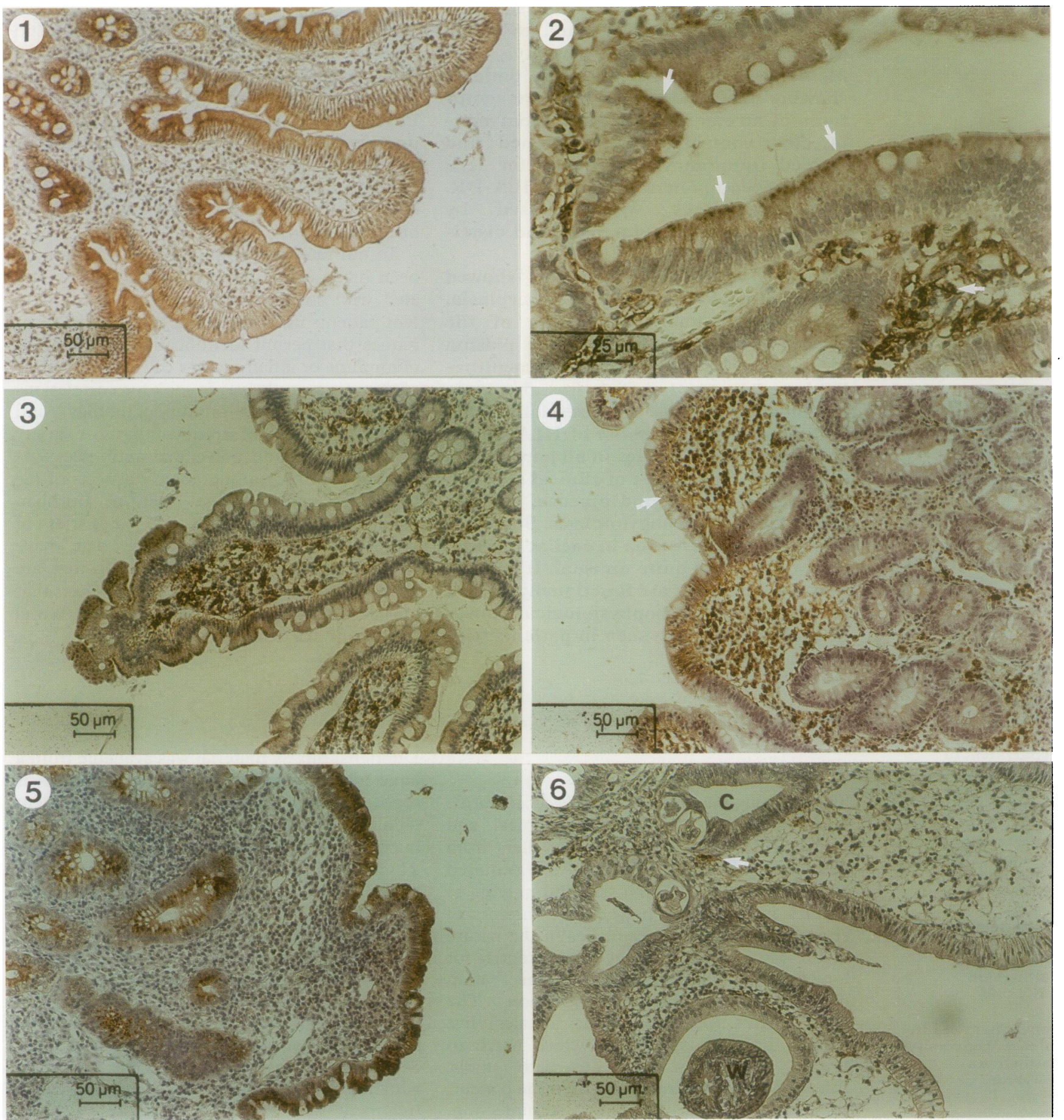

Figure 1 Immunocytochemistry of duodenal tissues stained for $H L A-D R$, secretory component (SC) or IgA. APC = antigen presenting cells; IEL = intraepithelial lymphocytes; $L P=$ lamina propria. Panel 1, normal tissue: SC expressed in crypt cells but not in enterocytes on the villi; panel 2, normal tissue: apical HLA-DR in enterocytes (arrowed) and HLA-DR positive APC in the LP (arrowed); panel 3, moderate strongyloidiasis: HLA-DR expression on enterocytes occurs primarily at the villus tip; panels 4-6, severe strongyloidiasis: panel 4, infiltration of epithelium by IEL (arrowed) and of $L P$ by IgA positive cells; panel 5, strong expression of SC in enterocytes and crypts; panel 6, virtual absence of HLA-DR positive enterocytes and APC (one arrowed). Parasites are present in the intervillous space $(W)$ and in the epithelium of the crypts $(C)$. 
Table 1 Mucosal immunopathological changes associated with severe strongyloidiasis

\begin{tabular}{llllll}
\hline Group & $\begin{array}{l}\text { Mucosal } \\
\text { morphology }\end{array}$ & $\begin{array}{l}\text { IgA positive } \\
\text { cells in LP }\end{array}$ & Staining for SC & $\begin{array}{l}\text { HLA-DR } \\
\text { positive enterocytes }\end{array}$ & $\begin{array}{l}H L A-D R \\
\text { positive APC }\end{array}$ \\
\hline Uninfected & Normal & Few & $\begin{array}{l}\text { Enterocytes negative } \\
\text { Crypt cells positive }\end{array}$ & Many & Many (LP of villi) \\
Severe symptoms & Villous atrophy & Many & $\begin{array}{l}\text { Enterocytes positive } \\
\text { Crypt cells positive }\end{array}$ & Few & $\begin{array}{l}\text { Few (LP of villi) } \\
\text { Many (villus tip } \\
\text { and epithelium) }\end{array}$ \\
\end{tabular}

$\mathrm{APC}=$ antigen presenting cell; $\mathrm{LP}=$ lamina propria; $\mathrm{SC}=$ secretory component.

nal (Behring, Lewes, Sussex, UK; ORCI O5) diluted 1 in 2000 for 30 minutes; antiHLA-DR mouse monoclonal (Dako, High Wycombe, UK; MO 746) diluted 1 in 40 for 60 minutes; anti-secretory component (SC) mouse monoclonal (Dako; A0187) diluted 1 in 1000 for 15 hours at $4^{\circ} \mathrm{C}$. All sections were counterstained with Harris's haematoxylin for five seconds.

\section{Results}

NORMAL DUODENUM

The material studied represented tissue collected from the duodenal bulb close to the pylorus, in which Brunner's glands occupied the submucosa and mucosa. In stained sections there were no indications of any histopathological changes in the mucosa. Few IgA positive plasma cells were observed in the lamina propria of the villi or in the loose connective tissue surrounding the intestinal crypts and Brunner's glands. SC was detected in the Golgi region and the cell membrane of the crypt cells but was absent from enterocytes on the villi (fig 1, panel 1). It was also seen in the cell membrane and weakly in the cytoplasm of the Brunner's glands. HLA-DR was expressed in the form of linear small granules in the apical pole of the enterocytes lining the intestinal villi (fig 1, panel 2). Numerous HLA-DR positive cells with a morphology equivalent to macrophage and dendritic cells (antigen presenting cells (APC)) were present in the lamina propria of the villi.

\section{PATIENTS PRESENTING WITH MILD SYMPTOMS}

The villi were shorter and broader than in controls and the lamina propria was infiltrated by lymphocytes and plasma cells, IgA positive plasma cells being concentrated in the lamina propria. Brunner's glands and crypt cells were positive for SC. The enterocytes lining the deepest portion of the villi also expressed SC. Enterocytes expressing HLA-DR occupied the upper two thirds of the villi. In the lamina propria, HLA-DR positive APC were concentrated in the medium and upper regions of the villi.

\section{PATIENTS PRESENTING WITH MODERATE} SYMPTOMS

Again, the villi were noticeably shorter and broader than in the normal controls. The lamina propria was oedematous and infiltrated by lymphocytes and IgA positive plasma cells. The latter were also present in the loose connective tissue around the Brunner's glands and crypt cells. The Golgi regions of the crypt cells were intensely positive for SC, as were the enterocytes lining the villi, with the exception of those located at the tip. Brunner's gland cells were also positive for SC. HLA-DR was expressed only by the enterocytes located close to the tip of the villi. APC were reduced in the lamina propria and were concentrated at the tip of the villi (fig 1, panel 3).

PATIENTS PRESENTING WITH SEVERE SYMPTOMS In some cases the flattening of the duodenal mucosal surface resulted in the complete loss of villi. A most striking feature was the infiltration of the epithelial layer by large numbers of intraepithelial lymphocytes and by a significant number of HLA-DR positive APC (fig 1, panel 4). Subepithelial aggregates of histiocytes were apparent and there were focal lymphoepithelial lesions infiltrating and surrounding the base of the crypts. The oedematous lamina propria was infiltrated by numerous IgA positive plasma cells and a few eosinophils. IgA positive plasma cells were also concentrated among the crypts and Brunner's gland secretory units. Both the crypt cells and the enterocytes lining the villi were SC positive, the stain being more intense than observed in patients with less severe symptoms. SC was also identified in the cell membrane and diffusely in the cytoplasm of Brunner's gland cells. Only a few groups of isolaced enterocytes were HLA-DR positive. HLA-DR positive APC in the lamina propria were greatly reduced (fig 1, panels 5 and 6). Eggs and larvae of the parasite were commonly present in the crypts, the eggs located between the epithelial cells and basal membrane, the larvae mainly located in the crypt lumen. However, there was little or no inflammatory reaction immediately around these stages (fig 1, panel 5).

The major changes associated with severe strongyloidiasis are summarised in table 1.

\section{Discussion}

The data presented add to existing knowledge of pathological changes in strongyloidiasis. Some changes - for example, the villous atrophy, crypt hyperplasia and IgA positive plasma cell infiltration, are similar to those in other parasitic infections-for example, giardiasis, ${ }^{6}$ as well as in coeliac disease ${ }^{7}$ and were proportional to the degree of clinical severity observed. Other changes are unusual and deserve particular comment. These include the reciprocal changes in HLA-DR and SC expression on enterocytes and the epithelial infiltration by intraepithelial lymphocytes and HLA-DR positive cells, which are unusual immunpathological responses to gastrointestinal infection. Histopathology similar to that seen in severe strongyloidiasis occurs in marasmus and kwashiorkor, associated with protein 
malnutrition. Malnutrition in strongyloidiasis has been described ${ }^{8}$ and was recorded in our patients with severe symptoms. Infection itself may cause reduced food intake, but the pathological changes in the intestine must also contribute to impaired nutrition.

The association of IgA positive plasma cells with the Brunner's glands and the expression of SC in these glands was a novel observation, suggesting that these structures may act as a route by which IgA enters the intestinal lumen. This observation has been confirmed subsequently in greater detail. ${ }^{10}$ In this study, the IgA positive lamina propria cell population increased proportionately with the severity of the symptoms so that, in patients with severe symptoms, infiltration of IgA positive plasma cells into the lamina propria of the villi extended to the intestinal crypts and the acini of the SC positive Brunner's glands. SC is essential for IgA transport into the intestinal lumen. In its dimeric form IgA is secreted by plasma cells near the intestinal crypts, and captured by specific SC receptors synthesised by the crypt cells. After intracellular transport, in the form of $\operatorname{sigA}$, antibody is delivered into the crypt lumen. ${ }^{11}$ As well as an increased expression in Brunner's glands in patients with strongyloidiasis, there was a progressive increase in SC positive cells towards the apex of the villi so that, in those with the severest symptoms, the villous epithelium was predominantly SC positive. The increased IgA secretion elicited by infection would require a greater number of epithelial cells able to transport the IgA into the gut lumen. Our findings are compatible with the noticeably increased amounts of $\operatorname{IgA}$ in duodenal secretions of patients with strongyloidiasis. ${ }^{13}$

The altered distribution of HLA-DR positive enterocytes in strongyloidiasis followed a pattern opposite to that of SC positive cells. In the normal intestine, the entire epithelial lining of the villi was HLA-DR positive, but in infected patients, as symptoms became more severe, there was a progressive reduction. In some patients with moderate symptoms only the upper third of the villi had HLA-DR positive cells and these disappeared completely in patients with the most severe symptoms. However, the reduced HLA-DR staining did not always parallel the clinical severity of disease.

These unusual, reciprocal changes in expression of SC and HLA-DR suggest that, with increasingly severe pathology, there is a gradual substitution of enterocytes capable of antigen presentation by cells that can deliver increasing amounts of sIgA into the intestinal lumen. This substitution must reflect influences upon normal enterocyte differentiation. Enterocytes are derived by mitosis of crypt cells and move towards the apex of the villi to detach at the apical extrusion zone as they differentiate. ${ }^{14}$ In strongyloidiasis, it seems that cell turnover is not accompanied by differentiation, expression of SC along the length of the villi remaining similar to that in the original crypt cells and HLA-DR expression being much restricted. If this interpretation is correct it can be assumed that the absorptive capacity of enterocytes may also be reduced, which may contribute to the malabsorption associated with this infection. ${ }^{15}$

The changes in cellular differentiation reflected in expression of SC and HLA-DR are presumably mediated by factors (probably cytokines) released from a variety of cells, including epithelial cells, in response to infection. Data from experimental models of intestinal helminthiasis would suggest that $T$ lymphocytes corresponding to the $\mathrm{T}$ helper subset should play an important role in the immunopathological responses to Strongyloides infection, and that interactions between Th1 and Th2 cells may determine the balance between resistance and susceptibility. ${ }^{16}$

This work was supported by research grants from the British Council/FACEPE Agreement, from the Conselho Nacional de Pesquisas, Bank of Brazil Foundation, and from the European Union.

1 Pelletier LL. Chronic strongyloidiasis in World War II Fa East ex-prisoners of war. Am $\mathcal{F}$ Trop Med Hyg 1984;33:5561.

2 Neva F. Stronglyoides stercoralis. In: Farthing MJG, Keusch GT, Wakelin D, eds. Enteric infection 2. Intestinal helminths. London: Chapman and Hall, 1995:87-105.

3 Almeida JR. O Strongyloides stercoralis, a estrongiloidiase e estrongiloidiase grave disseminada [dissertation]. Penamestrongiloidiase grave disseminada [dissertation]. PenamSchool, 1988.

4 De Paola D, Braga-Dias L da Silva JR. Enteritis due to Strongyloides stercoralis. Am $\mathcal{F}$ Dig Dis 1962;7:1086-98.

5 Coutinho HB, King G, Sewell HF, Tighe P, Coutinho VB, Robalinho TI, Carvalho AB. Immunocytochemical study of Peyer's patches follicular-assocaited epithelium in the marsupial Didelphis albiventris. Dev Comp Immunol 1993 17:537-48.

6 Nash TE. Giardia lamblia and giardiasis. In: Warren KS, ed Immunology and molecular biology of parasitic infections. 3r edn. Oxford: Blackwell Scientific Publications, 1993:157 69.

7 Perdue MH, McKay DM. Immunomodulation of th gastrointestinal epithelium. In: Wallace $\mathrm{JL}$, ed. Immunopharmacology of the gastrointestinal system. London: Academic Press, 1992:15-39.

8 Andrade ZA, Gomes MC. Pathology of fatal stronglyoidia sis. Rev Inst Med Trop Sao Paulo 1934;6:28-34.

9 Garcia FT, Sessions JT, Strum WB. Intestinal function and morphology in strongyloidiasis. Am F Trop Med Hyg 1977, 26:859-65.

10 Coutinho HB, Robalinho TI, Coutinho, VB, Amorin AM Almeida JR, Filho JTO, et al. Immunocytochemical demonstration that human duodenal Brunner's gland may participate in intestinal defence. $\mathcal{F}$ Anat 1996 189:193-7.

11 Scott H, Brandtzaeg P, Solheim BG, Thorsby E. Relation between HLA-DR-like antigens and secretory component (SC) in jejunal epitheium of patients with coeliac disease or dermatitis herpetiformis. Clin Exp Immunol 1981; 44:233-8.

12 Brandtzaeg $P$, Prydz $H$. Direct evidence for an integrated function of $J$ chain and secretory component in epithelia fransport of immunoglobulins. Nature 1984;311:71-3.

13 Bezjak B. Immunoglobulin studies in strongyloidiasis with special reference to raised serum IgE levels. Am $₹$ Trop Med Hyg 1975;24:945-8.

14 Leblond P, Stevens CE The constant renewal of the intestinal epithelium in the albino rat. Anat Rec 1948;100:35778.

15 Milner PF, Irvine RA, Barton CJ, Bras G, Richards R Intestinal malabsorption in Strongyoides stercoralis infestation. Gut 1965;6:574-81.

16 Locksley RM. Th2 cells: help for helminths. 7 Exp Med 1994;179:1405-7.$$
\text { . }
$$ 